У,K 340.1:343.7

ББК $67.0+67.408 .12$

DOI 10.22394/1682-2358-2019-3-19-26

A.V. Plakbov, Candidate of Sciences (Economics), Docent of the Civil Law Department, Central Russian Institute of Management, Branch of the Russian Presidential Academy of National Economy and Public Administration

A.V. Isaev, Candidate of Sciences (Politics), Docent of the Labor Law and Social Security Department, Central Russian Institute of Management, Branch of the Russian Presidential Academy of National Economy and Public Administration

\section{PROBLEMS \\ AND NOVELS \\ OF THE LEGISLATION \\ ON COUNTERING \\ THE LEGALIZATION \\ (LAUNDERING) \\ OF CRIMINAL \\ PROCEEDS}

The article focuses on the legal norms relating to countering the legalization of criminal proceeds. The problems of law enforcement practice are identified and measures are proposed to improve the current legislation in this area.

Key words and word-combinations: terrorism, legalization of income, money, credit organizations.
A.B. Плахов, кандидат экономических наук, дочент кафедры гражданского права Среднерусского института управления - филиала Российской академии народного хозяйства и государственной служби при Президенте РФ (email: plabov_a@mail.ru)

A.B. Исаељ, кандидат политических наук, дочент кафедрь трудового права и соииального обеспечения Среднерусского института упраљления - филиала Российской академии народного хозяйства и государственной службь при Президенте РФ (email: isaevlesha@yandex.ru)

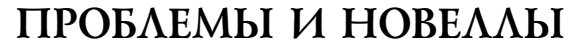

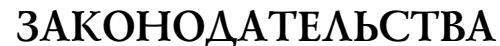 О ПРОТИВОАЕЙСТВИИ АЕГААИЗАЦИИ (ОТМЫВАНИЮ) АОХОАОВ, ПОАУЧЕННЫХ ПРЕСТУПНЫМ ПУТЕМ}

\footnotetext{
Аннотация. Рассматриваются правовые нормы, касающиеся противодействия легализации доходов, полученных преступным путем. Выявляются проблемы правоприменительной практики и предлагаются меры по совершенствованию действующего законодательства в данной сфере.

Ключевые слова и словосочетания: терроризм, легализация доходов, денежные средства, кредитные организации.
}

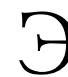
поха «столкновения цивилизаций» (по С. Хантингтону) и выбора мирового господства ици глобального мидерства (по 3. Бжезинскому) обусловцивает нетранс- 
парентность мировой политики. В Аанном контексте этнонациональная помемика и преследование узконаправленных политических и экономических интересов предопределяет распространение экстремистских идей. Как слеАствие - внутренние вооруженные конфликты, активизирующие деятельность террористических организаций. Это вцияет на состояние государственной безопасности в целом, а также детерминирует ряд противоправных действий в экономической сфере, совершаемых в џелях получения материальной выгоды, а также придания правомерного вида владению, пользованию или распоряжению денежными среАствами или иным имуществом, полученными в результате совершения преступления [1] .

В последнее Аесятилетие руководство России удемяет особое внимание Аанной проблематике - приняты как организационные меры, направленные на противодействие анацизируемым правонарушениям, так и ряд нормативных правовых актов. Например, целью профильного Федерального закона от 7 августа 2001 г. № 115-Ф3 явцяется борьба с теневым сектором экономики, а также защита прав граждан и государства от незаконных действий третьих миџ при осуществлении ими различных операџий, соответствующих опреАеленным критериям [1]. О необходимости противодействия терроризму в целом указывается в Стратегии национальной безопасности Российской Федерации (2015 г.). В п. 8 ст. 19 данного документа определены задачи по реализации направления устойчивого развития национальной финансовой системы [2]. В целях повышения уровня технического соответствия по Первой Рекомендации ФАТФ в 2018 г. была принята Концепция развития наџиональной системы противодействия мегализаџии (отмыванию) Аоходов, полученных преступным путем, и финансированию терроризма. Ее исполнение позволит эффективно противодействовать приданию правомерного вида использования незаконных денежных средств (имущества) и финансированию терроризма [3] .

Применение специальных экономических мер в цемях обеспечения безопасности предусмотрено п. 5 ст. 3 профильного Федерального закона «О безопасности» от 28 Аекабря 2010 г. № 390-Ф3 и нормами Федерального закона «О специальных экономических мерах и принудительных мерах» от 30 декабря 2006 г. № 281-Ф3. Кроме того, Амя обеспечения соответствия правовой и институциональной системы Российской Федерации требованиям Рекомендаций ФАТФ, а также наделения компетентных органов соответствующими полномочиями и проџедурами, принят ряд законодательных и иных нормативных правовых актов в отдельных неурегулированных областях (например, ФеАеральный закон от 23 апреця 2018 г. № 90-ФЗ, постановцение Правительства РФ от 11 сентября 2018 г. № 1081, постановление Правительства РФ от 26 октября 2018 г. № 1277, Федеральный закон от 23 апреля 2018 г. № 112-Ф3, Фелерацьный закон от 11 октября 2018 г. № 365-Ф3). В разъяснении пиенума Верховного Суда России от 26 феврамя 2019 г. указывается, что обналичивание криптовалют подпадает под нормы статьи УК РФ о мегализации имущества, приобретенного преступным путем [4].

В профильном Федеральном законе № 115-ФЗ установлен субъектный со- 
став правоотношений (табц. 1). К действиям, направленным на реализацию положений закона, относятся обязательный и внутренний контроль, а также запрет на информирование о мерах, предпринятых дия его соблюдения. ИскАючение составцяет информация о состоянии счета, его блокировке, отказе в заключении договора на банковское обслуживание или в проведении операций, а также о необходимости предоставления документов [1].

Категории субъектов

согласно Федеральному закону № 115-Ф3

\begin{tabular}{l|l}
\hline \multicolumn{1}{c|}{ Категория } & \multicolumn{1}{c}{ Субъекты } \\
\hline Физические лица & $\begin{array}{l}\text { Российские граждане } \\
\text { Иностранные граждане } \\
\text { Лица без гражданства }\end{array}$ \\
Организации и & Кредитные организации \\
индивидуальные & Участники рынка ценных бумаг \\
предприниматели & Страховые компании \\
Федеральная почтовая связь & Ломбарды и компании, занимающиеся скупкой драгметаллов, \\
& драгоценных камней и изделий из них \\
Устроители лотерей, тотализаторов и т.д. \\
Управляющие компании инвестиционных, негосударственных \\
пенсионных, паевых фондов \\
Занимающиеся операциями с недвижимостью \\
Потребительские кооперативы \\
Микрофинансовые организации \\
Операторы связи и т.д. \\
Иностранные структуры
\end{tabular}

Законодатель определяет норму, согласно которой контролю подлежат операции на сумму не менее 600 тыс. рублей (табл. 2) и операции, обладающие признаками необычной слелки. Санкцией за нарушение положений данного Закона является блокировка счетов клиента и отзыв мицензии у финансовой организации.

Критерии необычных сделок разработаны Федеральной службой по финансовому мониторингу в цемях реализации норм Федерального закона № 115-Ф3 в части ограничения противоправных операции с денежными средствами или иным имуществом [5]. Уполномоченным организациям и мицам рекоменАуется при разработке правиц внутреннего контроля учитывать критерии и признаки выявления необычных сделок в соответствии со спещификой Аеятельности данных акторов. Среди основных групп выдемяются как общие критерии необычных сделок, так и признаки подобных сделок с использованием бюджетных средств, при проведении операџий с денежными среАствами или иным имуществом в наличной форме и переводов денежных средств [5]. Указанный перечень имеет открытый характер. 
Таблица 2

Виды операций, подлежащие обязательному контролю в соответствии с Федеральным законом № 115-ФЗ

\begin{tabular}{|c|c|}
\hline Сумма сделки & Содержание операции \\
\hline$\geq 600$ тыс. рублей & $\begin{array}{l}\text { 1. Операции с денежными средствами в наличной форме. } \\
\text { 2. Зачисление или перевод на счет денежных средств, } \\
\text { предоставление или получение кредита (займа), операции с ценными } \\
\text { бумагами в ряде предусмотренных законодательством случаях. } \\
\text { 3. Операции по банковским счетам (вкладам). Абзац, касающийся } \\
\text { денежных средств во вкладе (на депозите) с оформлением } \\
\text { документов, удостоверяющих вклад (депозит) на предъявителя, } \\
\text { отменен с } 1 \text { июня } 2018 \text { г. } \\
\text { 4. Иные сделки с движимым имуществом }\end{array}$ \\
\hline$\geq 3$ млн рублей & Сделки с недвижимостью \\
\hline$\geq 100$ тыс. рублей & $\begin{array}{l}\text { Получение некоммерческой организацией средств и имущества от } \\
\text { иностранных государств и организаций или переводы в их адрес }\end{array}$ \\
\hline$\geq 10$ млн рублей & Операции организаций, имеющих стратегическое значение для ОПК \\
\hline $\begin{array}{l}\text { Независимо } \\
\text { от суммы }\end{array}$ & $\begin{array}{l}\text { Операции, в которых один из участников сделки - лицо, } \\
\text { подозреваемое в участии в экстремистской деятельности }\end{array}$ \\
\hline
\end{tabular}

Важно, что описание категорий и признаков в Рекомендациях частично корреспондирует с Положением о требованиях к правилам внутреннего контромя кредитной организаџии в цемях противодействия мегализации (отмыванию) доходов, полученных преступным путем, и финансированию терроризма, утвержденным Банком России 2 марта 2012 г. № 375-П. В этих документах наблюдается определенная терминологическая дифференциация, что требует корректировки с точки зрения юридической техники. В целом, если операция подпадает поА один из пунктов перечня, кАиент обязан предоставить банку документы, подтверждающие чистоту сделки.

В соответствии со ст. 7 Федерального закона № 115-ФЗ первичной обязанностью организаций, осушествляющих операции с денежными средствами или иным имуществом, явмяется идентификаџия клиентов и их бенефициарных владельцев согласно определенным критериям [1]. Эта обязанность не решает проблемы предотвращения отмывания нелегальных доходов, так как простой идентификаџии клиентов может быть недостаточно. С нашей точки зрения, верификация клиентов в данном случае будет более эффективна. Обосновать ее введение можно, ссылаясь на то, что преимушественное большинство подозреваемых миџ Аибо миџ, участвующих в сомнительных сделках, действуют, как правимо, через подставных физических миџ или компании.

Обновление идентификаџионной информаџии должно происходить минимум оАин раз в гоА, а при возникновении сомнений в ее актуальности и истинности - в течение семи рабочих дней. Негосударственные пенсионные фонды должны обновлять информацию о застрахованных не реже одного раза 
в три года, но при возникновении подозрений в недостоверности информации обязаны перепроверить ее в течение семи рабочих Аней.

В обязанности организаций, совершающих операции с Аенежными средствами, входят также фиксация и предоставление уполномоченному органу в трехАневный срок следующей информации по операциям, подмежащим обязательному контролю: вид операции, причины дия ее совершения, дата операции, сумма. Кроме того, финансовые организации обязаны предоставцять информацию по запросам уполномоченного органа в порядке, установленном Центробанком РФ.

Финансовые организации обязаны блокировать денежные средства и другое имущество кмиентов, вкмюченных в перечень экстремистов и террористов. БАокирование должно происходить незамедиительно, но не позАнее одного рабочего дня с момента внесения изменений в перечень экстремистов. Проверка присутствия клиентов в данном перечне Аолжна проводиться не реже одного раза в три месяџа. При возникновении подозрений, что деятельность клиента может иметь незаконный характер или он контактирует с миџами и организациями, имеющими отношение к подобной деятельности, кредитная организация имеет право на следующие действия: во-первых, отказать клиенту в закцючении договора на банковское обслуживание в соответствии с правилами внутреннего контроля; во-вторых, расторгнуть договор, если в течение года клиенту не менее двух раз было отказано в проведении операций по причине непреАставления им сведений, подтвержАающих чистоту сделки; в-третьих, отказать в проведении операџии по поручению клиента на пять рабочих дней.

Коммерческим банкам запрещается открывать счета без мичного присутствия клиента мибо его законного представителя, а также без представления ими информации, необходимой для идентификации. Это ограничение не действует, если клиент или его представитель были идентифицированы ранее. Запрещено также открывать счета в случаях, когда существует подозрение, что данный счет может быть использован клиентом в операциях по цегализации средств.

Аля документов, содержащих сведения, указанные в ст. 7 Федерального закона № 115-Ф3, и сведения, необходимые Аля идентификации мичности, преАусмотрен пятилетний срок хранения. Анкета (Аосье) клиента также хранится в кредитной или некредитной финансовой организации не менее пяти мет.

Росфинмониторинг может принять решение о замораживании всех счетов физического или юридического мица, если есть обоснованные подозрения в его участии в террористической деятельности или он включен в перечень участвующих в ней $и ц$. Решение о блокировке счетов незамедиительно размещается в Интернете на сайте регумятора. Ограничения могут быть отменены в судебном порядке. Физическим мицам, к которым применены подобные меры, можкет назначаться ежемесячное пособие в размере десяти тысяч рублей. Имущественные претензии третьих миџ, возникшие в резуиьтате блокирования счетов, удовлетворяются через суд. Судебные издержки в Аанном случае возмещаются за счет средств на заблокированных счетах ответчика или иного имущества.

Поскольку в Федеральном законе № 115-ФЗ не определены четкие критерии обоснования подозрений участия в террористической деятельности, то принимаемые на их основе решения финансовых организаций могут быть 
не всегда законными. Восстановление своих прав через суд часто ведет к затратам или убыткам, возникающим у клиента вследствие блокировки счета. ОАнако нарушение финансовой организацией положений Федерального закона № 115-ФЗ может привести к отзыву миџензии. Аица, виновные в нарушении законодательства, несут ответственность в соответствии с ГражАанским, ААминистративным и Уголовным кодексами РФ [6-7].

Таким образом, проблема правоприменительной практики заключается в том, что, с одной стороны, кредитные организации обязаны учитывать критерии и признаки необычной сделки (ввиду аАминистративной ответственности), а с Аругой - формальный подхоА в Аанной сфере приводит к бцокировкам счетов без запросов документов / сведений от клиентов.

Согласно анализу существа и динамики рассмотрения судебных споров по системе «Кциент - Банк» по первой инстанции, за последние Аесять мет рассмотрено порядка 1500 дец. Это свидетельствует о значительном количестве организаџий, ограниченных в пользовании банковскими услугами; при этом нельзя с полной уверенностью утвержлать, что заблокированные транзакции (460 000 сомнительных транзакций на сумму 180 мирА руб.) Аействительно мегализовали преступный доход. Это подтверждают апемляционные процедуры: более половины исковых заявлений к банкам были удовлетворены [8] .

По мнению экспертов, сегодня в России насчитывается свыше ста тысяч «недобросовестных миџ», которых можно отнести как к правонарушителям, так и к тем, кто не смог прибегнуть к квалифицированной юридической помощи [8]. Согласно официальным отчетам Росфинмониторинга, в 2018 г. решениями Межведомственной комиссии по противодействию финансированию терроризма удалось заблокировать доступ к финансовой системе Российской Федерации более чем семидесяти миџам, проходящим по материалам совместной проверки Росфинмониторинга и ФСБ России на причастность к террористической деятельности, на счетах которых заморожкено около 5,8 млн рублей. Эффективно задействовались такжке инструменты внесудебной заморозки. Кроме того, развивая систему пресечения финансирования терроризма, с 2018 г. регулятором активно используется инструмент принятия решения о неразрешении въезда в

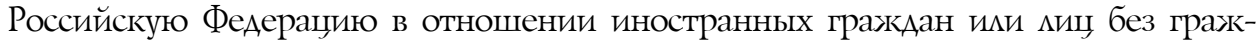
Аанства, представляющих угрозу национальной безопасности страны. Так, в рамках предотвращения нанесения репутационного ущерба Российской Федерации в ходе подготовки и проведения Чемпионата мира по футболу в России проведена совместная проверка в отношении десяти тысяч физических миц. В отношении более семидесяти киџ ФСБ России принято решение о нежелательности их пребывания на территории Российской Федерации.

Аанные финансовых расследований Росфинмониторинга использовались ФСБ России при возбужжении более девяноста уголовных Аел по минии противодействия финансированию террористической и экстремистской деятельности. Так, совместными действиями на территории Краснодарского края, Республики Аагестан и Республики ААыгея пресечена деятельность управляемой с территории Сирии законспирированной ячейки, осуществлявшей сбор и переправку денежных средств на нужаы запрещенной в Российской ФеАерации 
межАународной террористической организаџии «Исламское государство». По заданию эмиссаров МТО чиены радикальной ячейки под видом благотворительности организоваци сбор и переправку денежных среАств Аля ресурсного обеспечения своих связей в Сирийской Арабской Республике. В ходе мероприятий вскрыты и задокументированы схема и механизм финансирования членов террористической организации на общую сумму свыше 10 млн рублей. Материалы Росфинмониторинга способствовали возбужлению трех уголовных Аел по ст. 205.1 УК РФ («Содействие террористической деятельности»). В рамках следственных действий трое подозреваемых задержканы и арестованы по решению суда. В ходе обысков по адресам их проживания изъяты средства коммуникации, платежные инструменты и фискальные чеки, а также иные Аокументальные материалы, подтверждающие их преступную деятельность. Также были арестованы семь чиенов ячейки международной террористической организации «Ажебхат ан-Нусра», участвовавших в финансировании сирийских боевиков и действовавших в Московском регионе, Республике Аагестан и Чеченской Республике [9].

В связи с этим отметим, что «подозрительные» транзакции требуют более тщательной проверки. Усиленный контроль кмиентов банками сказывается и на операционных издержкках, которые существенно возросли с введением закона о мегализации. В цемях снижения издержек коммерческие организации ввели заградительный тариф Аля ряда клиентов. Аанный механизм по своей природе схожк с комиссией за выдачу кредита, взымаемую банками в 2010-2012 гг. Основное отличие от комиссии за проведение операции - ее существенный размер (выше стандартного тарифа в 5-20 раз [8]. На практике вопрос о правовой квалификации подобных тарифов остается дискуссионным [10-11].

В целом кредитные организации оказываются в ситуации, когда необходимо вести бизнес с имеющимися клиентами в условиях соблюдения требований Федерального закона № 115-ФЗ. В Аанных условиях банки выбирают Ава варианта деятельности: кибо соблюдать все досконально, создавая неудобства клиентам излишне формальным подходом, мибо выбрать более агрессивную

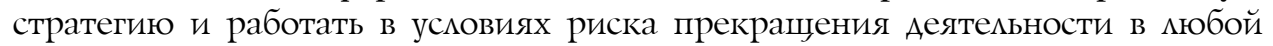
момент. В такой ситуации возможно установцение ответственности кциентов за невыполнение требований банков преАставить запрашиваемые документы, а также предоставцение банкам права замораживать средства на счетах.

В целях совершенствования законодательства в данной сфере необходимо законодательно установить минимум условий использования банковских карт, который поможет мегальным хозяйствующим субъектам не попасть поА внимание служббы безопасности банка и предотвратит возможную блокировку карты (счета) согласно Федеральному закону № 115-ФЗ. В случае блокировки карты возникают негативные последствия дия клиента, а дия разблокировки карты и счетов в соответствии с действующим законодательством необходимо предоставить документы, подтвержАающие законность получения денежных среАств.

После принятия Федерацьного закона № 115-Ф3 государство должно было получить следующие выгоды и блага: снижение коррупции в разцичных ветвях власти и государственных структурах; вывод из теневого (нелегального) 
бизнеса огромного количества денежных средств и перенаправление их в развитие экономики страны; предотвращение финансирования терроризма. ОАнако на практике особенности применения данного Закона выгмядят несколько иначе: услуги обслуживания и возврат денежных средств с банковских счетов стали невозможными дмя добропорядочных граждан, предпринимателей, юридических миџ, честно ведущих финансовые дела и вовремя платящих налоги. Коммерческие банки постоянно направцяют требования юридическим и физическим мицам о предоставлении разАичных документов, объяснений, выписок, подтвержАающих мегальность происхождения средств, которые явмяются честно заработанными, что вызывает негодование, возмущение и дискомфорт при осуществлении бизнеса. Это свидетельствует о значительных пробелах действующих нормативных правовых актов в области цегализации доходов и требует незамедиительного принятия мер по Аальнейшему совершенствованию законодательства в данной сфере, при этом важно, чтобы законодательный механизм в первую очередь служиц охране законных интересов граждан и государства в целом.

\section{Библиографический список}

1. О противодействии легализации (отмыванию) доходов, полученных преступным путем, и финансированию терроризма: Федер. закон от 7 авг. 2001 г. № 115-Ф3 (в ред. от 18 марта 2019 г.) // СЗ РФ. 2001. № 33, ч. 1. Ст. 3418; 2019. №12. Ст. 1223.

2. О Стратегии экономической безопасности Российской Федерации на период до 2030 года: Указ Президента РФ от 13 мая 2017 г. № 208. URL: https://www.garant.ru/products/ipo/prime/ doc/71572608/\#review

3. Концепция развития национальной системы противодействия легализации (отмыванию) доходов, полученных преступным путем, и финансированию терроризма (утв. Президентом РФ 30 мая 2018 г.). URL: http://kremlin.ru

4. О судебной практике по делам о легализации (отмывании) денежных средств или иного имущества, приобретенных преступным путем, и о приобретении или сбыте имущества, заведомо добытого преступным путем: постановление Пленума Верховного Суда РФ от 7 июля 2015 г. № 32 (в ред. от 26 февр. 2019 г.). URL: https://base.garant.ru/71119624/

5. Об утверждении Рекомендаций по разработке критериев выявления и определению признаков необычных сделок: приказ Росфинмониторинга от 8 мая 2009 г. № 103 (в ред. от 9 янв. 2014 г.) // Финансовая газета. 2009. № 39.

6. Изутина C.B. Неисполнение требований законодательства о противодействии легализации (отмыванию) доходов, полученных преступным путем // Современная наука: актуальные проблемы теории и практики. Сер.: Экономика и право. 2018. № 3. С. 153-155.

7. Денисов А.Б. Легализация (отмывание) преступных доходов как один из источников финансирования террористической деятельности // Сборник статей международной научно-практической конференции «Проблемы взаимодействия науки и общества». Тамбов, 2018. С. 147-151.

8. Ефремов В. Отчет: «115-Ф3: правоприменение закона о противодействии и легализации. URL: https://bosfera.ru/pdf/Conf_sud_Efrmenko.pdf

9. Отчет о деятельности Росфинмониторинга. URL: http://www.fedsfm.ru/content/files/activity/annualreports/otchet_2018\%20\%D1\%80\%D1\%83\%D1\%81.pdf

10. Ащурова С.Ю. Отказ в совершении операции клиента и заградительные тарифы кредитных организаций // Электронный сборник статей по материалам XLVIII студенческой международной научно-практической конференции. Новосибирск, 2018. С. 200-207.

11. Лысова Ю.В. О заградительных тарифах в банковской практике // Право и экономика. 2016. № 2 (336). C. 59-65. 